\title{
O pensar intuitivo como fundamento de uma educação para a liberdade ${ }^{1}$
}

\section{Intuitive thinking as the foundation of education toward freedom}

\author{
Jonas Bach Junior ${ }^{2}$
}

\begin{abstract}
RESUMO
Este artigo apresenta o conceito de pensar intuitivo de Rudolf Steiner. O pensar racional alcança apenas um nível de apreensão da realidade. Por uma observação fenomenológica do pensar, torna-se possível a qualidade intuitiva do pensar. O produto e o produtor estão em unidade nesta observação. A autoeducação do sujeito é o processo de uma educação para a liberdade. Então, a conquista de nível intuitivo exige um aperfeiçoamento cognitivo por meio de um caminho heurístico. Agir no mundo com base na consciência intuitiva é fundamento de uma ética superior. O sujeito pode estabelecer diretrizes autênticas para sua ação quando se autoeduca.
\end{abstract}

Palavras-chave: Steiner; fenomenologia; pensar intuitivo; autoeducação.

\begin{abstract}
This paper introduces the concept of intuitive thinking of Rudolf Steiner. The rational thinking only reaches one level of apprehension of reality. Through a phenomenological observation of thinking, the intuitive quality of thinking becomes possible. The product and producer are in unity in this observation. The subject's self-education is the process of education toward freedom. So the achievement of the intuitive level requires a cognitive improvement through a heuristic path. Acting in the world based on intuitive awareness
\end{abstract}

DOI: $10.1590 / 0104-4060.41520$

1 Pesquisa financiada com bolsa do programa conjunto entre a Coordenação de Aperfeiçoamento de Pessoal de Nível Superior e o Serviço Alemão de Intercâmbio Acadêmico. O artigo faz parte da tese de Doutorado: "A Pedagogia Waldorf como educação para a liberdade: reflexões a partir de um possível diálogo entre Paulo Freire e Rudolf Steiner", defendida em 27 de fevereiro de 2012, na Universidade Federal do Paraná.

2 Universidade Estadual de Campinas. Campinas, São Paulo, Brasil. Av. Bertrand Russell, $n^{\circ}$ 801. CEP: 13083-865. 
is the foundation of a higher ethic. The subject may establish authentic guidelines for his action when he educates himself.

Keywords: Steiner; phenomenology; intuitive thinking; self-education.

\section{Introdução}

A educação está vinculada a um processo de aquisição de consciência. Impera como referência para a formação desta consciência, a razão humana. Normalmente, compreende-se a qualidade da consciência dentro dos parâmetros culturais e históricos de como a racionalidade foi exercida. É o aguçamento no uso da racionalidade que faz a consciência convencional do senso comum atingir o patamar filosófico. É a restrição na abrangência da racionalidade, empregada para fins utilitaristas, que produz o reducionismo em sua versão instrumental e - subsequentemente - a reificação da consciência.

Não é muito comum encontrar autores que explorem níveis de consciência embasados numa faculdade humana superior à razão. A possibilidade de se desenvolver a capacidade intuitiva da consciência é fundamental na teoria de Rudolf Steiner para se compreender o sentido de uma educação para a liberdade. O pensar intuitivo é uma categoria dentro de um processo de observação fenomenológica do ser humano. A observação do pensar é o ponto de partida para o seu desenvolvimento que só pode ser realizado por autoeducação.

A palavra intuição remete, em geral, no cotidiano, ou a uma noção vaga de alguma coisa, um pressentimento de um fato, ou à crença na capacidade própria de captar a verdade de algo diretamente sem o processo de pensar a respeito. Em ambos os casos, ela se revela como uma sensibilidade extra que o indivíduo possui, podendo até não dominá-la. É a intuição que decide acontecer no indivíduo, este não a faz repetir-se quando bem quer; ela é fortuita, ocasional, sua aplicação é um risco, uma aposta. Diz-se que possui boa intuição aquele que tem uma grande proporção de acertos. Para explicar exatamente como ela acontece e por que ela ocorre mais em alguns do que em outros, há várias interpretações. De certa forma, ela é inconsciente, no sentido de manter-se inapreensível em seu processo de formação; o fator consciente é o resultado imediatamente fornecido à consciência. Estas definições estão longe do conceito de pensar intuitivo. 


\section{Processo fenomenológico do pensar intuitivo}

Steiner descreve um conjunto de etapas meditativas que indicam ao sujeito cognoscente sua aplicação prática para a efetiva comprovação. Este método é a revelação de um procedimento individual que conduz o próprio cognitor à constatação de sua veracidade. No processo metodológico, o sujeito se insere no aspecto heurístico para o desenvolvimento do pensar intuitivo. Isto envolve um processo de educação da própria atividade reflexiva. O primeiro passo é observar a dinâmica da própria observação, para depois constatar os fatores fundamentais e opostos do ato cognitivo: o perceber e o pensar. Na observação do pensar, a atividade pensante e o conteúdo pensado coincidem. A intencionalidade da consciência, dirigida para esta observação vivenciada, é o fator que proporciona o estado de exceção. A atividade pensante e o conteúdo pensado não coagem a consciência, pois é a sua própria intencionalidade que determina o conteúdo pensado. A apreensão deste nível da atividade mental não redunda no pensamento discursivo, ela ocorre imediatamente à sua execução, ou seja, sem qualquer abordagem intermediária ou processos de dedução ou demonstração.

Steiner (2004, p. 45) destaca o estado de exceção na experiência do pensar. A normalidade encontra-se em observar o objeto primeiro e depois pensá-lo. Porém, observar o pensar é um fenômeno sui generis, distinto, peculiar e extraordinário. Para tê-lo como elemento de observação, ele tem que primeiro criar a si próprio, para depois contemplar-se; a concomitância de contemplar-se e criar-se é absurda, exige dois sujeitos num mesmo. O ser pensante não avalia o pensar enquanto pensa, sua atenção está dirigida ao objeto durante a observação, neste momento o pensar mantém-se inobservado. Esta é a primeira observação sobre o pensar, o seu caráter oculto. Durante a observação do pensar, o pensar observado já virou objeto, aquele que se encontra em atividade permanece oculto mesmo quando quer compreender a si próprio; entretanto este objeto é imediato, distinto de todos os conteúdos das outras observações, que são mediadas. Os nexos congruentes que correlacionam os objetos da experiência comum são encontrados fora do campo da observação, porém, estes nexos são imediatamente dados nos conteúdos (conceitos) da experiência do pensar, no próprio campo de observação. O pensar como experiência no pensar está sob um regime de exceção, é um princípio que "traz à consciência o que no caso de todas as outras atividades mentais permanece inconsciente". (STEINER, 2000, p. 37).

Para perceber o conteúdo pensado é verdadeira a atuação do pensar. Como observação que se apodera da verdade sem a razão, sem o conhecimento analítico ou discursivo, o pensar é conscientemente intuitivo. $\mathrm{O}$ fenômeno do 
pensar que compreende a si mesmo acontece na e pela consciência. Portanto, o pensar baseado em si mesmo e que se autoconhece não diz respeito à sensibilidade humana; ele é uma intuição da atividade mental consciente de si própria.

O pensar intuitivo é a vivência da própria atividade, não é um patamar onde o ser humano chega em sua evolução mental e ali se estabelece. Ele não é o ponto de chegada, é o ponto de partida para uma inédita ampliação da realidade para o homem. O racionalismo é um modo específico de explorar a razão como meio de abordagem à realidade, no entanto, o pensar vivenciado é uma atividade além do racionalismo, sem retroceder ao irracional. Não há prescrição de formas fixas para a manifestação do pensar vivenciado, este permite à consciência do sujeito a compreensão do seu estado mental e a percepção da gênese de sua atividade. O pensar vivenciado é:

[...] uma nova perspectiva no desdobramento do pensamento, diferente do intelecto analítico que incorreu na racionalidade quantificadora. Esta forma de pensar, pelo fato de não se fixar em objetivações, mas despertar para a observação de processos plasmadores subjacentes às mesmas é a intuição consciente que integra o homem de modo individual, como ser acional na dinâmica de uma realidade sempre emergente e em transformação. $\mathrm{O}$ pensar intuitivo consciente abre o horizonte para uma nova dimensão da produção filosófica, que ultrapassa a perspectiva da mera interpretação de textos e da destruição crítica de posições alheias e se incorpora à vida do indivíduo como prática meditativa. O pensamento intuitivo, que brota do silêncio meditativo, é capaz de superar o materialismo e convertê-lo em passo intermediário necessário na busca pela realização da autonomia espiritual plena do ser humano. (VEIGA, 1998, p. 91).

A auto-observação do pensar pode ser designada como uma experiência imaterial, elevando a consciência do sujeito a um nível mais intenso, possibilitando a vivência do processo que configura dinamicamente a consciência. O pensar vivenciado não luta contra autoridades externas, nem sofre coações de qualquer natureza, pois não há submissão alguma. Uma vez engendrada sua atividade, necessita ser reativada e assim, paulatinamente, se tornar capacidade adquirida através de um processo de educação que o próprio sujeito empreendeu. Ao imbuir-se do seu teor intuitivo, o pensar vivenciado possibilita uma reformulação positiva da subjetividade, pois os valores e significados herdados ao longo da existência são destituídos de sua "naturalidade". O pensar intuitivo abre à percepção da gênese cognitiva operante na essência do indivíduo. 
Além disso, o agir é o complemento no mundo do conceito pensado. O conceito livre das amarras do mundo sensorial, das sujeições do sujeito, estabelece novas diretrizes à ação humana. A revisão biográfica a partir do pensar experienciado abre as portas à genealogia da moral do sujeito individual a ele mesmo. O que fazer, aqui e agora, toma um novo sentido. "Na medida em que ele promove a reviravolta da consciência e passa a observar a observação, adquire o olhar para o processo que fundamenta a sua consciência objetal natural e se assume concomitantemente na dimensão acional de sua existência”. (VEIGA, 1998, p. 90).

O pensar vivenciado não permite arqueologia, esta vai no encalço dos vestígios do pensar, lida somente com os despojos dele. O pensar tem a fonte de sua vivacidade na eterna atividade do espírito. A ele não interessa prender-se à análise de suas pegadas, melhor é saber e decidir como se realiza cada "pisada", para aprimorar seu "caminhar" pensante. O pensar analítico vive dos rastros, o intuitivo vive no ato traçante.

A fonte do núcleo essencial do pensar está no centro universal que se manifesta de modo multiforme e infinito. A essência do pensar é a própria intuição consciente, que não se limita a nenhuma forma cristalizada, pois ela é o ato que se autodetermina, a liberdade em si. Em sua manifestação, é sempre uma forma, contudo, coerente e dialógica em relação ao objeto percebido.

Um pensamento, para manter-se definido estavelmente, precisa do sujeito para segurá-lo nessa forma estática. Ele não é um elemento inicial de qualquer fato, pelo contrário, é a etapa final de um processo intimamente vinculado ao eu, que sempre esteve no centro de onde emanam os pensamentos. (STEINER, 1980, p. 119).

A observação fenomenológica do pensar apreende a gênese, o processo e o resultado, no seu todo é uma intuição consciente, é atividade realizada pelo eu. A atividade do eu não se dissocia no âmbito da consciência, pois está inserida na consciência, pela consciência mesma. $\mathrm{O}$ estado de exceção do pensar intuitivo é uma elevação da consciência, que atinge uma nova dimensão caracterizada pelo domínio que o sujeito tem de si mesmo e por intenção própria. O pensar intuitivo estabelece novos parâmetros de interpretação e ação no mundo. Sua efetivação permite ao indivíduo a superação da subjetividade e, paulatinamente, a identificação com sua individualidade. O processo do pensamento intuitivo é catalisador de transformações da consciência natural e da vida cotidiana. Quando o sujeito tem a possibilidade de reconhecer no ato cognitivo a atividade que forma o objeto da consciência, ele pode aplicá-la ao campo da ação. Assim, o conteúdo gerado pelo pensar intuitivo se transfere ao mundo sensorial. (STEINER, 1980, p. 145). 
A vivência da essência do pensar é um método autoeducativo. Sua conquista pressupõe sua aplicação disciplinada para se tornar capacidade adquirida. É a individualidade que determina a intensidade do processo de transparência consigo mesma. Não ocorre uma constituição espontânea ou instantânea da individualidade, tampouco se pode projetar alguma expectativa de domínio e garantia em relação ao devir do mundo. $\mathrm{O}$ autoconhecimento gerado pela atividade consciente intuitiva dirige para o aspecto genuíno da individualidade, por outro lado, exige novos acessos. A experiência adquirida através desse processo permite uma comparação, para discernir entre o que é efêmero e o que é permanente e se baseia em si mesmo. (STEINER, 2000, p. 162). As conquistas de uma individualidade em sua existência e sua libertação em relação às características da espécie perfazem o sentido steineriano de evolução da consciência. O foco não é dirigido para as circunstâncias externas e materiais, a evolução da consciência intuitiva exige outros fatores. A exceção cabe nos casos em que a constituição psíquica e física não possibilita que a atividade intuitiva se torne fenômeno fisiológico. A individualidade é uma superação das limitações da subjetividade, ela continua o percurso evolutivo e vai além do nível alcançado no plano biológico e cultural. A ideia evolutiva estava presente no passado como formadora do organismo, no presente, quando consciente na atividade auto-observada, ela compreende sua atuação e cria o seu próprio conteúdo.

O método da observação fenomenológica do pensar inverte a direção da intencionalidade da consciência. De um modo geral, os métodos assumem como objeto os fenômenos que manifestam o espírito, mas não o espírito em si. A atenção é dirigida ao espelho, à imagem reflexa, porém, não ao ser que se espelha. É possível orientar o espelho, a atividade reflexiva, em diversas direções, assim nasce o perspectivismo, ou seja, uma imagem diferente da outra, de acordo com a orientação do espelho. Especulação é a atividade que gira o espelho e cria a diversidade de perspectiva. O ponto fixo é o "eixo" do espelho, é o ser que se deixa espelhar e que permanece não observado. A especificidade do ser revela a sua individualidade. O que é único e singular tem expressão permanente. (STEINER, 2004, p. 103). Duas forças entram em questão, elas se expressam na dinâmica entre o refletido e o refletor. O refletido é facilmente abordado pelo intelecto, o ponto problemático é a apreensão do refletor, que exige continuamente a ativação da observação fenomenológica. O pensar intuitivo é a atividade que mantém o refletor consciente de si. Se esta retroatividade cessa, o refletido exerce o seu predomínio. O refletido não é mera figura de linguagem, tampouco quer dizer passividade, pois é tácita a subjugação humana às redundâncias e paixões, como expressariam Deleuze e Guattari (1996, p. 31), ao "buraco negro da subjetividade". 
Liberdade para Steiner não é condição estática, é estado dinâmico evolutivo permanente na realização do conceito de espírito livre. Este conceito não é dado, não vem pronto, é constantemente construído e captado pela instância específica do ser humano que compõe sua individualidade. Steiner enfatiza que o teor verdadeiro e autêntico de uma individualidade não é o seu aspecto fortuito, mas a instância que gera a manifestação. Todo ser humano individual é parcialmente individualidade e parcialmente espécie. (STEINER, 2000, p. 164). Quando no decurso existencial um ser agrega a si caracteres pertinentes à primeira parcela, ele evolui em (direção à) liberdade. A última parcela pertence ao âmbito genérico.

Toda a reflexão de Steiner mantém uma confiança no pensar humano, nas capacidades latentes que este possui e que podem ser despertadas e desenvolvidas. Atualmente prepondera um pessimismo com relação à atividade pensante humana, principalmente devido às consequências da aplicação da racionalidade instrumental para o progresso econômico, bélico e tecnológico. Corriqueiramente os sujeitos expressam - ao se referirem a si mesmos - a noção superficial de utilizar seu pensar, quando podem estar simplesmente concatenando blocos de representações conforme hábitos mentais arraigados e adquiridos segundo o modelo de seu contexto cultural. Este modo coletivo de representar e formular mentalmente um conjunto de representações é a reprodução de uma percepção cultural. $\mathrm{O}$ pensar como atividade baseada em si mesma não tem referência particular para o seu modo de atuar. Aliás, são todas as modalidades de aplicação do pensar que se fundamentam nele próprio.

O pensar intuitivo é um cogito não convencional, não se limita à fixidez deste ou aquele cogito, de um ser cultural, um modo repetitivo de pensar. O homem como objeto de percepção tem representações que são uma afirmação sobre si que ignoram o que o sujeito é em si, são os jogos de linguagem da subjetividade. Para reconhecer o cogito intuitivo que Steiner descreve é necessário um eu que o estabeleça. Sou eu que reconheço a verdade de sua possibilidade. Sou eu que verifico a direção do meu pensar - ao mesmo tempo em que o pensar mantém o reconhecimento do eu - para atingir o objetivo mencionado. É o processo de inspecionar-se que evita as quedas nas tendências subjetivas, na inércia do hábito ou da memória. Eu não pressuponho um traçado costumeiro da minha maneira pensante, não há determinismo sobre o conteúdo. Pelo contrário, a exploração pesquisante multifacetada está em aberto. O pensar intuitivo é a ideia (atividade em si) imediata. Porém, diante do mundo, diante das percepções, é o pensar como força na fantasia moral que toma o conceito universal e o une ao conteúdo percebido, gerando a representação moral.

O pensar ao qual Steiner se refere não é um ser cultural com características singulares. Qualquer descrição extensiva de sua atuação está vinculada a uma 
subjetividade. O pensar intuitivo está liberto das percepções, utiliza-as para dar forma à representação moral que lhes cabe. Não é a busca de exatidão, as representações acuradas são o desdobramento de um pensamento analítico que crê encontrar na minuciosidade descritiva do objeto a certeza da verdade. Porém, isto é apenas uma especialização na complexidade das percepções. O intelecto, como fragmentador, continua recortando a realidade percebida e tornando mais complicada a ligação que a razão tem como tarefa sobre os elementos isolados. A escala progressiva do labor intelectualista isola, fragmenta e especializa cada vez mais. Sua atividade disjuntiva e disruptiva dão origem à complexidade reordenadora da razão, que precisa estar muito ativa para redescobrir os elos desfeitos.

Como regime metodológico de observação fenomenológica do ser humano, Steiner estabelece o pensar intuitivo como exercício inicial da liberdade humana e não especula sobre as etapas finais: escolha e consumação. Este exercício nada mais é do que o processo de aprendizado, porém não encetado externamente, mas estimulado por impulso próprio. O âmbito educativo da observação fenomenológica do ser humano é um processo de autoeducação. Abordar o cerne humano pela via representativa é manter-se no nível da subjetividade. A experiência do eu, objetivamente dada, acontece pela via intuitiva. (ZIEGLER, 2006). O pensar vivenciado, em si, é infindável, não há limites para sua expressão, pois é atividade baseada unicamente em si mesma. A frequente recorrência ao pensar consciente da vivência de si abre um leque de desdobramentos e torna-se competência interna adquirida por intenção própria. Com o processo no tempo, pode-se ampliar a experiência sobre diferentes percepções, em momentos diferenciados, em situações distintas, com o outro. A condição primordial do ser livre está na ausência de qualquer coação determinante do conteúdo pensado. A experiência do pensar intuitivo é também vivência de um vácuo, não há nada que oriente o valor de um objeto a não ser a própria essência do eu que mantém sob seu domínio a consciência. A experiência da consciência intuitiva influi na consciência natural e filosófica, revelando o que subjaz ao processo de defrontar-se com a realidade. A vida cotidiana e natural não permanece intacta com a aplicação frequente do método intuitivo.

Steiner (1955, p. 595) comenta sobre os possíveis desdobramentos do pensar que está além da consciência natural. Ele revela resultados dentro de um processo de amadurecimento da efetivação do pensar na alma ${ }^{3}$. Não há uma classificação dos processos desencadeados, o destaque é para sua intensificação que aborda o sentir e o querer com uma progressiva potencialização. É na qualidade do maior poder de concentração que ele exerce seu domínio sobre

3 A descrição está na obra "Os Enigmas da Filosofia" (Die Rätsel der Philosophie), publicada em 1914, 20 anos depois d" "A Filosofia da Liberdade". 
âmbitos da personalidade (sentir, querer) que são aparentemente "naturais" e autônomos. Se quiséssemos exemplos palpáveis, teríamos que pesquisar uma personalidade em si. Descrever qual tonalidade assumiu o individualismo ético e o pensar intuitivo em Rudolf Steiner seria uma amostra. Mesmo assim, o teor a ser descrito seria somente um retrato desta personalidade, um exemplo ocasional. O pensar intuitivo é inormatizável. A descrição do perfil de configuração da intuição consciente de alguma personalidade abre-se ao risco de ser tomada como norma. Como não cabe nenhuma normatização, o individualismo ético engendrado pelo pensar experienciado é irrepetível. Este nível de consciência elevado requer constante reacesso, não por hábito formal, mas por atividade conscientemente pretendida. O que se repete é a intenção do eu por intermédio do domínio de si na consciência, mas o teor ideativo é sempre renovado. Em sua irrepetibilidade, o pensar intuitivo é continuamente problemático e problematizante, questiona as coações internas corriqueiras. Como não pode ser genericamente tipificado, ele se plasma como um tipo único em si, a unicidade (uniqueness) do tipo. Uma avaliação de seus efeitos sobre a vida e sobre a consciência natural está circunscrita ao interesse da própria individualidade. Se a avaliação seguir com procedimentos dissecativos ela se afasta da fonte viva, tenta reconhecer o valor através de análise posterior ao efetuante atuante. $\mathrm{Na}$ análise, recorre ao discurso, mas não porta a força. Como avaliação comparativa no campo social ela é estéril.

Como depende de processo heurístico, a intuição consciente é intransferível. Falar sobre ela é trazer em comum a consciência das etapas do método intuitivo. Porém, ela não é experiência textual, perceber alguém falando sobre ela não é percebê-la. No próprio indivíduo a intuição consciente é corrigível, plasmável, não se dá de um único modo. No âmbito do pensar vivenciado, Steiner sempre adjetiva a individualidade com a qualidade superior de legítima, genuína e autêntica. $\mathrm{O}$ teor supremo da verdade de si é critério de autoexigência para o discernimento próprio. É inclusive estímulo à dúvida, ao autoquestionamento para checar e averiguar cada voz interna, o quanto esses dizeres internos são propriedade exclusiva da personalidade ou são oriundos de algo alheio a ela.

$\mathrm{Na}$ intuição conceitual, sujeito e objeto estão em unidade plena. Mas é unidade conquistada e não dada. O pensar vivo é fenômeno de esforço, é o oposto da inércia da intelectualidade. A intuição consciente é observação ativa da lei da essência conceitual. O problema dessa constatação é o hábito arraigado de vivenciarmos com mais frequência a cristalização do processo pensante, as representações mentais. Há tantos perfis de pensamento no mundo quanto mentes humanas, esse é o reino das representações. Mas os pensamentos têm uma só origem, os conceitos. A representação é a inércia do pensar. Energia é requisitada para se chegar ao cerne do processo pensante. Neste cerne, acorda- 
-se dentro da consciência para algo que repousa em si. O eu domina a si. Para que este nível de domínio seja constatado, há a necessidade de um processo autoeducativo com este objetivo. Este domínio superior de si é a expressão da liberdade humana em Steiner. É a superação das coações internas. No cerne do pensar a vivência é da real liberdade, pois qualquer ato produtivo só se estabelece a partir da própria atividade.

O pensar intuitivo não é acumulação quantitativa, não é mero gerador de informação, ele é o suporte que torna possível a informação. Sua acumulação é qualitativa, acontece na própria experiência e vivência de si. Na obra "Os Enigmas da Filosofia"4, Steiner analisa o percurso evolutivo do pensar na filosofia ocidental desde os gregos e considera seus estágios como etapas preliminares ao nível superior do pensar como experiência no pensar. Se a consciência natural já dista da consciência científica ou filosófica, a consciência intuitiva se estabelece em grau próprio. Se a capacidade de alcançar tal nível na consciência não foi (não é) prerrogativa de muitos filósofos, pode-se questionar se há espaço para aqueles que vivem na consciência natural. Pois se muitos pensadores falharam, sendo representantes de ápices da inteligência humana, mesmo quando investiram toda sua existência no desvendar da vida interna, que expectativa pode ter alguém com a consciência natural, que sequer participa do exercício filosófico, de tentar resultados com o método intuitivo? Steiner reivindica uma efetiva aplicação do método para obtenção de algum sucesso. Se este é o meio para o que se denomina a verdadeira liberdade humana, esta estaria restrita a um grupo seleto. O restante, então, teria que se contentar com o que possui: um pálido esboço da sua individualidade à deriva no comércio abundante das subjetividades.

A fenomenologia estrutural concerne o conhecimento como o processo de unificação da realidade com o eu. (WITZENMANN, 1983). Os modos comum, científico e filosófico de pensar separam o eu da realidade. Pertencem à consciência ordinária e são graus imprescindíveis, pois à medida que isolam a realidade do eu, permitem a este, em sua solidão, possuir a consciência de si. Pelos sentidos, o eu se vê isolado, porém, só conhece a si porque se isola. Steiner não refuta a experiência sensorial, como se fosse um entrave ou o desvio da evolução espiritual humana. O materialismo consequente à ênfase sensorialista é um estágio necessário para o eu adquirir consciência de si. Mas Steiner ressalta que o verdadeiro autoconhecimento é atingido quando o eu integra a realidade em si novamente, por mérito próprio, autonomamente. Copiar o mundo é permanecer numa pseudorrealidade. A consciência ordinária não tem subsídios para resolver os profundos mistérios da existência humana. $\mathrm{O}$ mundo sensorial não se basta

4 [Die Rätsel der Philosophie]. (STEINER, 1955). 
a si mesmo, a dependência exclusiva em relação a ele é geradora de um vazio. Segundo Steiner (1955, p. 610), o caminho para a região interna da alma não é conhecido pelos filósofos modernos e até mesmo o pensamento hegeliano está circunscrito à consciência ordinária ${ }^{5}$. A fonte onde a experiência da alma tem sua origem não é alcançada pela reflexão crítica nem pela teorização. A consciência ordinária lida com a observação da experiência anímica que é o fundamento para a consciência do eu. A consciência superior intuitiva pressupõe um método para o domínio do cerne existencial e que é para ser vivido e experimentado, não para ser estudado ou teorizado. Reflexões a respeito não revelam o vigor despertado por sua efetivação.

Os pensamentos amplamente racionalizados abarcam a ambivalência do agir humano. Não há ato que beneficie uns sem prejudicar outros; não há ação que transforme as coisas e seja unicamente benéfica. A consciência pós-moderna da ambivalência ética não supera a contingência da atuação do eu moral no mundo. Ajudar o outro, dependendo das circunstâncias, pode ser facilitar ou dificultar para o outro. Dependendo da relevância de uma decisão, os conceitos de vantagem ou desvantagem, facilidade ou dificuldade, individual ou coletivo, não resolvem a questão. Eles podem propulsionar um jogo sem fim de parâmetros que definem as consequências de um resultado de certa atividade (uma percepção). A ambivalência é justamente a consciência da não unilateralidade da existência. A consciência da ambivalência é a representação mental do fato. O pensar intuitivo é a intensificação e o aprofundamento da atividade pensante do ser individual para encontrar o conteúdo ideativo que determina a sua própria vontade. A ambiguidade das consequências do seu ato não trabalha como peso sobre a balança decisória intuída. O peso significativo é conferido pela intuição conceitual que é simultaneamente força motriz em sua vontade e motivo ético em seu querer. Não é a cultura, nem a época, a localização, a interação social, ou a subjetividade do indivíduo que determinam a vontade da ação. Estas instâncias cedem e abrem espaço à determinação contundente do querer intuído.

As reflexões de Steiner (2000, p. 124) não tratam de diagnosticar todos os limites para uma ação em liberdade. Ele reconhece as barreiras físicas e históricas que impedem a liberdade. O objetivo steineriano é evidenciar onde reside a possibilidade da liberdade, é revelar qual instância humana é o ensejo para uma ação autenticamente ética. O próprio indivíduo pode ser o seu limite, uma vez que há indivíduos com poucas ideias que necessitam receber de outros os conteúdos ideais. Porém, mesmo os indivíduos ricos em ideias podem

5 "Pois também o vivenciar dos pensamentos de Hegel transcorre ainda no campo desta simples consciência". (STEINER, 1955, p. 610, tradução nossa). [Denn auch Hegels Gedankenerleben verläuft noch in dem Bereiche dieses gewöhlichen Bewußtseins.] 
limitar-se à sua imaginação moral pouco desenvolvida (não transforma suas ideias em representações morais quando está diante dos fatos da vida), ou não possui técnica moral, ou seja, não possui conhecimento aprofundado sobre o fenômeno (objeto) no qual quer atuar.

Outro limite que pode ser acrescentado é a rejeição do grupo social no qual o indivíduo se encontra, caso este não consiga traduzir suas ideias ou não consiga se fazer aceito por aqueles que estão em seu entorno. Neste caso, se o seu intento depende de muitas forças, a solidão pode manter a intuição conceitual somente no plano das ideias. Este é o risco do pensamento steineriano, sua tendência platônica de iniciar a exploração pelo mundo das ideias e ficar por ali mesmo, sua permanência no idealismo não leva à concretização objetiva na realidade. $\mathrm{O}$ individualismo ético resolve a questão da individualidade quando esta depende unicamente de si mesma para a concretização de seus intentos. Se a conquista da meta intuída conceitualmente for dependente exclusivamente da vontade da individualidade, a ação genuinamente livre se concretiza na realidade. Entretanto, se uma individualidade necessita da colaboração alheia para atingir suas metas éticas ideais individuais, ela passa a procurar outros meios para atingir tal fim. A individualidade pode exercer uma influência carismática sobre outros e despertar o querer alheio com suas intuições conceituais. Isto dependerá de uma série de fatores influentes, dentre eles: sua capacidade de se fazer entender no cotidiano comum - trazer em palavras compreensíveis e aceitáveis o conteúdo dos conceitos intuídos para aqueles que acolherão estes em suas vontades; a flexibilidade do grupo social na aceitação de ideias renovadoras e sua capacidade de empreender tarefas desafiadoras; a afinidade entre as intenções intuídas por um indivíduo e a expectativa de grupo em geral. A atualidade é uma época de desaparecimento do carisma. (WEBER, 1982, p. 177). O mundo, quanto mais civilizado, mais pragmático se torna. Despertar a vontade alheia não é mais questão somente de persuasão ou de disseminar o entusiasmo coletivo, através de uma exposição convincente da congruência e pertinência das ideias intuídas de uma individualidade. Há também o enfrentamento da inércia mental da coletividade humana, atrelada aos seus hábitos mentais subjetivos e condicionados à redução do consumismo.

Quando um ideal intuído depende da força motriz de muitos indivíduos, a individualidade portadora deste ideal necessitará de recursos materiais para encetar suas metas. As limitações físicas e históricas vinculam-se ainda ao potencial cultural de uma individualidade e ao campo de relações sociais. Para uma individualidade não redundar num idealismo sonhador, ela necessita de um querer que se proponha a superar todos esses impasses da realidade e que possa viabilizar pelo reconhecimento alheio ou institucional, a consciência coletiva da relevância e prioridade de suas intuições conceituais para o social. 
Fora a questão do social, adentra-se aqui em outro problema para a individualidade: definir a proporcionalidade da importância pecuniária para delinear a finalidade de sua vida. É passível o reconhecimento do dinheiro como poderoso estímulo da ação humana. Uma meta que tem por representação mental a obtenção de ganhos monetários é mais estimulante que outras representações. O status social, o poder, o conforto, a aquisição de bens e segurança material, etc., operam como conceitos que se tornam o leitmotiv existencial geral. Estar sob a posse de recursos financeiros significa disponibilizar um dispositivo de aquisição do trabalho alheio, é um signo de poder. Compra-se o processo do outro, adquire-se o resultado do processo. O dinheiro como mecanismo de mobilização da vida econômica e social, e como fator de rompimento do tempo e do espaço que potencializou a vida moderna, serve tanto aos desejos inferiores quanto aos altos ideais. Vivemos num sistema social onde a finalidade da vida de muitos é a representação mental pecuniária e não os ideais humanos.

O ser humano em função do ganho como finalidade da vida, não mais o ganho em função do ser humano como meio destinado a satisfazer suas necessidades materiais. Essa inversão da ordem, por assim dizer, "natural" das coisas, totalmente sem sentido para a sensibilidade ingênua, é tão manifestamente e sem reservas um Leitmotiv do capitalismo, quanto é estranha a quem não foi tocado por seu bafo. (WEBER, 2004, p. 46-47).

Nesse sentido, é o homem que serve aos objetivos mera e exclusivamente econômicos, invertendo a ideia de que a economia existe para servir ao homem. A última é um ideal a ser conquistado e praticado, o primeiro são representações compartilhadas culturalmente (o espírito da lucratividade e monetarista). O dinheiro permite concretizar representações (percepções) e concretizar ideais (conceitos). A fantasia moral pode driblar a falta de recursos e buscar representações adequadas à condição objetiva da existência de uma individualidade. Uma grande dependência pecuniária e a sua indisponibilidade podem significar o adiamento da consecução dos ideais ou a desistência se o querer não for tão forte. A falta de recursos pode se tornar o ensejo de grande desenvolvimento da vontade própria que insiste no esforço superador ou fonte de ressentimento social e do desalento existencial. O excedente de recursos pode significar tanto a ampla realização espiritual, quanto a lassidão, o consumismo, a distração, a prepotência. 


\section{Conclusão}

Em relação à parcela de ideais nos quais o fator pecuniário é imprescindível, a individualidade estará sob a decisão de empreender todos os seus esforços, de que maneira e por quanto tempo for necessário para tentar obter o que necessita. Se a intenção de Steiner é desenvolver um idealismo objetivo, não se pode ficar restrito somente à abstração dos conceitos sobre liberdade, pensar intuitivo e individualismo ético. A compensação ao idealismo é o seu vínculo ao objetivo. $\mathrm{O}$ dinheiro é uma questão da vida concreta. O campo filosófico abre espaço à concretude da existência e no campo social o processo decisório é também um fator político, que define quais ideais serão realizados e de quais individualidades.

Os diagnósticos sobre os limites à liberdade são vastos, operam como discurso crítico que revela o perigo da unilateralidade do idealismo, mas são igualmente a justificativa para alguns em decretar prévia e absolutamente a impossibilidade da ação livre. Concernindo ao âmbito da possibilidade, as reflexões steinerianas receberiam a mesma crítica sofrida pela fenomenologia, de se tornar especulação possibilitária.

O debate em Steiner não é político, é existencial. A genuína individualidade irá se perguntar se o seu agir está imbuído de um querer próprio, ou se o seu agir é involuntário. Descobre a parcela livre e a parcela não livre do seu existir. Evoluir, em Steiner, recebe o sentido de uma continuidade de aplicação da vitalidade na direção da realização de conceitos morais intuídos pelo pensar livre. É um redirecionamento existencial a partir da concepção consciente da finalidade da vida individualizada para dar segurança e impulso aos motivos do querer. A individualidade é livre quando a sua finalidade existencial é espiritualizada, individualizada. Ela é não livre quando a finalidade de sua vida está adaptada aos anseios alheios (conforme o pai quer, a igreja quer, ou alguma outra autoridade quer). A finalidade opressora que expurga o sentido da vida é uma finalidade extra-humana. A opressão ocorre quando o conceito do efeito, que determina a causa do agir, é imposto externamente.

O pensar livre, na acepção steineriana, é uma qualidade da consciência que atingiu o nível intuitivo. Este patamar de abrangência e profundidade da consciência e de sua relação com a realidade só é atingível por um processo de autoeducação que vai além da racionalidade. O processo só é verificável e executável por uma observação fenomenológica do e pelo ser humano. 


\section{REFERÊNCIAS}

DELEUZE, Gilles; GUATTARI, Félix. Mil platôs - capitalismo e esquizofrenia. Rio de Janeiro: Ed. 34, 1996. v. 3.

STEINER, Rudolf. A filosofia da liberdade: fundamentos para uma filosofia moderna: resultados com base na observação pensante, segundo método das ciências naturais. São Paulo: Antroposófica, 2000.

STEINER, Rudolf. A obra científica de Goethe. São Paulo: Associação Pedagógica Rudolf Steiner, 1980.

STEINER, Rudolf. Die Rätsel der Philosophie: in ihrer Geschichte als Umriss dargestellt. Dornach (Suíça): Rudolf Steiner Verlag, 1955.

STEINER, Rudolf. O método cognitivo de Goethe: linhas básicas para uma gnosiologia da cosmovisão goethiana. São Paulo: Antroposófica, 2004.

VEIGA, Marcelo da. Experiência, pensar e intuição - introdução à fenomenologia estrutural. São Paulo: Cone Sul, 1998.

VEIGA, Marcelo da. Posfácio. In: STEINER, Rudolf. A filosofia da liberdade: fundamentos para uma filosofia moderna: resultados com base na observação pensante, segundo método das ciências naturais. São Paulo: Antroposófica, 2000.

WEBER, Max. A ética protestante e o "espírito” do capitalismo. São Paulo: Companhia das Letras, 2004.

WEBER, Max. Ensaios de sociologia. Introdução de H. H. Gerth e C. Wright Mills. Rio de Janeiro: LTC, 1982.

WITZENMANN, Herbert. Strukturphänomelogie: Vorbewußtes Gestaltbilden im erkennenden Wirklichkeitenthüllen: Ein neues wissenschaftstheoretisches Konzept im Anschlu $\beta$ an die Erkenntniswissenschaft Rudolf Steiners. Dornach (Suíça): Gideon Spicker Verlag, 1983.

ZIEGLER, Renatus. Intuition und Ich-Erfahrung: Erkenntnis und Freiheit zwischen Gegenwart und Ewigkeit. Stuttgart: Verlag Freies Geistesleben, 2006.

Texto recebido em 25 de maio de 2015.

Texto aprovado em 11 de junho de 2015. 
